\title{
The Relationship between Consciousness of Professional Role and Work Autonomy of Rural Teachers from Sichuan Province
}

\author{
Tianmei Zhou ${ }^{*}$, Jiewei Chen ${ }^{2}, \mathrm{Li} \mathrm{Luo}^{3}$ \\ ${ }^{1}$ School of Educational Science, Neijiang Normal University, Neijiang, China \\ ${ }^{2}$ School of Foreign Languages, Neijiang Normal University, Neijiang, China \\ ${ }^{3}$ School of Geography \& Resources Science, Neijiang Normal University, Neijiang, China \\ Email: ${ }^{2}$ zhtm6566@aliyun.com
}

Received August $15^{\text {th }}, 2013$; revised September $16^{\text {th }}, 2013$; accepted October $15^{\text {th }}, 2013$

\begin{abstract}
Copyright (C) 2013 Tianmei Zhou et al. This is an open access article distributed under the Creative Commons Attribution License, which permits unrestricted use, distribution, and reproduction in any medium, provided the original work is properly cited.
\end{abstract}

\begin{abstract}
The paper has discussed the characteristics of consciousness of professional role of rural teachers and the relationship between consciousness of professional role and work autonomy. By randomly sampling, a survey is conducted among 265 primary and secondary school teachers from Sichuan province. It is found that the whole consciousness of professional role of rural teachers from Sichuan province is above average; the role consciousness of their collaborators and facilitators is the highest; the role consciousness of their social and economic status is the lowest. From the characteristics of different groups of teachers, there is no difference in gender, teaching age and education background, but there are significant differences between teachers of urban and rural areas, backbone teachers and nonbackbone teachers, teachers in key middle schools and non-key middle schools, and among teachers who teach Chinese, mathematics, foreign languages, Politics, History, Chemistry, Biology, Geography and teachers in primary and middle schools. Consciousness of professional role of teachers is significantly related to work autonomy. That is to say, consciousness of professional role of teachers can positively or negatively predict work autonomy.
\end{abstract}

Keywords: Rural School Teachers; Consciousness of Professional Role; Work Autonomy

\section{Introduction}

Professional role is divided according to the role of groups and is the role of the social members playing in professional positions (Ding \& Zhang, 1992). Consciousness of professional role, the individual's ideology, is the realistic, clear, stable and organized reflection to the job, which refers to awareness, cognition and understanding to individual's professional role status, professional role norms, professional role behavior (Feng, 2006). For the connotation of teacher professional role consciousness, most researchers regard that it is teachers' cognition and understanding of their professional role, that is, the teachers' awareness of role is their own cognition to the teachers' professional norms and is the social role expectations reflecting in the teachers' mind (Jiang, 2008); The more comprehensive definition is Liang Yuhua's view. He regards it as the teachers' perceiving, cognizing, understanding and experiencing to their own role status, corresponding role behavior standards and role playing (Liang \& Pang, 2005). It includes three basic structures: cognizing and understanding their role positions, understanding their norms, as well as cognizing and experiencing the role playing role. They influence and interact mutually and form a whole that cannot be separated.

Many practices and studies have found that teachers' educational concept is one of the important factors to improve the teachers' diathesis and educational conduct, especially the pro-

\footnotetext{
*Corresponding author.
}

fessional role of teachers which has influence on the teachers' professional development, and even the children's growth and development. Most studies have focused on the research that how the teacher's role consciousness "should be", but ignore the research on the status quo of the teachers themselves and their opinions. Even if there are some studies about it, fewer researchers have investigated rural middle school teachers' professional role consciousness. So, the research is to investigate the status quo of the rural middle school teachers' consciousness of professional role and to provide targeted strategies for the rural teachers' pre-service education and teachers' on-thejob training. The research will be beneficial to guide teachers in rural areas to correctly perceive themselves, examine their attitude towards profession, and find profession's significance for themselves. It will also help enrich the education of researches in rural teachers in our country and provide empirical evidence for the research on the specialization of teaching profession.

Job autonomy is that the job gives the individual of freedom, independence and discretion to schedule work and to decide how to work, which is one of the five core characteristics of job (Fang \& Ding, 2007). It refers to "the degree the individual gains freedom, independence and discretion in work schedule and working program decision" (Menlo Hackman \& Oldham, 1980). In the field of education, the work autonomy of teachers is also very important. It is the autonomy to their own subjective world or inner self, which is their psychological characteristics to adjust positively and control the educational and tea- 
ching activities driven by intrinsic motivation, under the guidance of certain social norms and educational purpose (Yao \& Shen, 2010). A lot of studies show that teachers' work autonomy has close relationship with their work motivation, satisfaction, stress, job burnout (or separation from service), anxiety, specialization, creativity, sense of responsibility and so on (Yang, Xia, \& Huang, 2009). Teachers' consciousness of occupational role occupies the core status in the teachers' educational concept, which affects teachers' other educational concepts and education behaviors directly. So, the second purpose of this study is to investigate the close relationship between teachers' professional role consciousness and teachers' work autonomy as well as the prediction effect.

\section{Methods}

\section{Participants}

The researchers collected 280 questionnaires and 265 are valid. In detail, there are 45 elementary school teachers, 177 junior middle school teachers and 43 senior middle school teachers; 119 male teachers and 147 female teachers; 191 rural teachers and 69 urban teachers. There are 85 samples selected randomly from Neijiang rural teachers and 180 selected from Sichuan "national training of the backbone teachers in disaster areas' rural junior middle schools".

\section{Research Materials}

Teachers' professional role consciousness questionnaire: The study adopts the self-designed questionnaire of middle school teachers' professional role consciousness. The questionnaire includes 3 parts, 6 dimensions, and 23 items. Three parts include teachers' cognizing and understanding of their role status (social economic status, knowledge imparter and executor, researcher and curriculum developer, collaborator and facilitator), understanding of their role norms as well as cognizing and experiencing of the role playing. The six dimensions are role consciousness of social and economic status, role consciousness of knowledge imparter and executor, role consciousness of researcher and curriculum developer, role consciousness of collaborator and facilitator, consciousness of professional role norms and consciousness of professional role experience. In the present research, every factor of the scale's $\alpha$ coefficient is between .54 to .89 and half reliability is between .56 to .84 . The whole scale's $\alpha$ coefficient is .90 , and half reliability is .85 . It means that the questionnaire has good reliability. Exploratory factor analysis shows that the rate of the 6 factors' cumulative variance contribution is $60.79 \%$, which proves its validity. It is a five-point Likert scale. The minimum score of each tested item is 1 point, and the top score is 5 points. Higher values indicate higher degree of professional role consciousness approval.

Teachers' work autonomy questionnaire: The study adopts Teachers' work autonomy questionnaire developed by Yang Bing et al. (Yang, Xia, \& Huang, 2009), which contains 28 items, 6 factors: the autonomy of school operation management, the autonomy of professionalization and curriculum reform, the autonomy of classroom teaching, the autonomy of student performance assessment, the autonomy of carrying out extracurricular activities, and the autonomy of student behavior management. The Cronbach's $\alpha$ coefficients of the questionnaire and each dimension are: $.89, .89, .75, .74, .91, .70$ and .94 , the $\alpha$ coefficient of the whole questionnaire is .90 ; the 6 factors' cumulative variance contribution rate is $55.36 \%$. Both the reliability and the validity of the scale meet the requirement of psychometrics. The questionnaire uses Likert-5 points scoring system from 1 to 5 ; the higher the scores, the stronger job autonomy.

Demographic variables questionnaire: This questionnaire mainly records personal data, including gender (male and female), region (urban and rural), teachers' titles (primary teacher, secondary teacher, senior teacher), teaching subjects (Chinese, Math, English, Politics, History, Chemistry, Biology, Geography, and so on), school types (key and non-key middle schools), teacher's types (backbone or non-backbone teachers).

\section{Procedure and Data Analysis}

In the form of questionnaire investigation, investigators were assumed by the trained principals or class teachers. Questionnaires were retrieved on the spot after teachers finished. The data are processed by SPSS12.0 statistics software.

\section{Results}

\section{The General Situation of Rural Teachers' Professional Role Consciousness}

Mean comparison found that overall, the average score of the consciousness of rural teachers' professional role $(3.77 \pm .52)$ is greater than 3 . The six-dimension scores of rural teachers from high to low in turn are as follows: role consciousness of rural teachers' collaborators and facilitators $(4.35 \pm .84)$, consciousness of occupational role norms $(4.34 \pm .71)$, role consciousness of knowledge imparters and executors $(3.80 \pm .68)$, role consciousness of researchers and curriculum developers $(3.70 \pm .74)$, consciousness of professional role experience $(3.26 \pm .82)$, role consciousness of status $(3.08 \pm 3.08)$. It shows that Sichuan rural teachers' recognition of consciousness of professional role is above average. The recognition of role consciousness of their collaborators and facilitators is the highest and the recognition of consciousness of their economic and social status is the lowest.

\section{The Comparisons of Sichuan Rural Teachers' Consciousness of Professional Role among Different Groups}

The rural teachers' role consciousness of collaborators and facilitators and understanding of role norms are obviously higher than urban teachers'. To the contrary, the rural teachers' role consciousness of status is obviously lower. There are no regional differences in role consciousness of knowledge imparters and executors, role consciousness of researchers and curriculum developers and consciousness of occupational role experience. Rural backbone teachers' consciousness (role consciousness of knowledge imparters and executors, role consciousness of researchers and curriculum developers, role consciousness of collaborators and facilitators, and consciousness of professional role norms) is obviously higher than the non-backbone teachers'. The key middle school teachers' consciousness (role consciousness of researcher and curriculum developers, role consciousness of collaborators and facilitators and consciousness of occupational role norms) is distinctly lower than the general middle school teachers'. The role consciousness of knowledge 
imparters and executors and consciousness of professional role norms of the rural teachers who teach Chinese, Math and English are distinctly higher than those teachers who teach Politics, History, Chemistry, Biology, Geography and other subjects. There are no differences in consciousness of professional role between the primary school and middle school teachers, except for role experience.

To investigate the consciousness differences between primary and middle school teachers, and teachers with different titles, the researchers use LSD post hoc tests (Table 1) and find that: the consciousness of professional status of rural senior high school teachers is distinctly higher than primary and secondary school teachers' $(P<.05)$, but role consciousness of knowledge imparter and executor is significantly lower than theirs. For the role consciousness of knowledge imparter and executor, role consciousness of collaborator and facilitator, and consciousness of professional role norms, secondary school teachers' are significantly higher than primary and senior high school teachers' $(P<.05)$. For the role consciousness of collaborator and facilitator, and consciousness of occupational role norms, primary school teachers' are distinctly higher than senior high school teachers' $(P<.05)$. Additionally, senior teachers are significantly higher than teachers in the second rank of teaching in the role consciousness of collaborator and facilitator as well as consciousness of occupational role norms $(P<.05)$.

\section{Correlations between Rural Teachers' Consciousness of Professional Role and Work Autonomy}

The result (Table 2) shows that there are significantly positive correlations between teachers' role consciousness of status and each dimension of work autonomy, and between consciousness of occupational role experience and each dimension of work autonomy. And other dimensions of professional role consciousness are positively related to the autonomy of student performance assessment, of student behavior management, of carrying out extra-curricular activities and of class teaching, and are negatively related to the autonomy of school operation management and of professionalization and curriculum reform.

On the basis of the above correlation analysis, the researchers apply regression analysis to put dimensions of work autonomy as the dependent variables and dimensions of professional role as predicting variables. The result (Table 3) shows that teachers' role status, researcher and developer, collaborator and facilitator, role norms, and role experience can significantly predict the different dimensions of work autonomy. Specifically, teachers' role consciousness of status can significantly and positively predict five dimensions (except class teaching) of work autonomy (between $\beta$ in $.207 \sim .475, P<.05$ ); role norms can positively predict two dimensions of autonomy of student performance assessment and the autonomy of carrying out extra-curricular activities( between $\beta$ in $.287 \sim .305, P<.01$ ), and can negatively predict the autonomy of professionalization and curriculum reform $(\beta=-.304, P<.01$; teachers' role experience can positively predict two dimensions of carrying out extra-curricular activities and class teaching (between $\beta$ in .167 $\sim .270, P<.05$ ); teachers' role consciousness of collaborator and facilitator an positively predict two dimensions of autonomy of class teaching and the autonomy of student behavior management (between $\beta$ in .286 .420, $P<.001$ ); lastly, teachers' role consciousness of researcher and curriculum developer can negatively predict the autonomy of school operation man- agement $(\beta=-.279, P<.01)$. The total explanation rate of teacher's role consciousness to different dimensions of work autonomy is $5.1 \% \sim 18.1 \%$.

\section{Discussion}

\section{Characteristics of Rural Teachers' Consciousness of Professional Role}

This study shows that the overall approval of Sichuan rural teachers' consciousness of professional role is on the average, role consciousness of collaborator and facilitator being the highest and consciousness of social and economic role status being the lowest. It states that due to the dynamics and rapid change of the modern social knowledge, teachers are no longer the owner and imparter of the knowledge. Rural teachers have changed their role cognition on authority representatives and pure knowledge imparter of knowledge. They gradually set up the equal consciousness that the students are the facilitators of the study, and that they are the students' mentors and facilitators on study. In the meantime, implementation of new curriculum reform in our country has obtained certain achievements in the recent ten years; however, in the process of implementation," the teachers' participation is far from what reform advocates expected", which means teachers should become a researcher and developer of the new curriculum, but not merely the receivers, practitioner and consumer of the new curriculum $(\mathrm{Wu}$, 2009). Additionally, because of the restrictions of their own objective conditions and subjective factors, rural teachers cannot or are unwilling to actively participate in the new curriculum reform, rural teachers' approval of the consciousness as the role of curriculum developer and researcher is not high, and they can't grasp the role norms accurately and comprehensively. The teachers are also full of confusion on the role norms, which are their own role rights, responsibilities, and conduct standards. At the same time, salary is a special concern for the teachers. In recent years, salary increases year by year, but rural teachers' income growth is so small that many teachers can't feel the change of the income and they are not satisfied with the income gap between urban and rural areas (Zhang \& Ye, 2010). Additionally, because of rural teachers' work environment and working pressure, their approval of consciousness on the social and economical status is the lowest.

From the perspective of different group characteristics, the rural teachers' consciousness of professional role has no significant difference in gender, teaching aging, and education background, but has prominent difference in the urban and rural teachers, backbone and non-backbone teachers, key schools and non-key schools, Chinese-Math-English and other subjects' teachers as well as primary and middle school teachers. 1) The consciousness differences between urban and rural, key and non-key schools may be related to the strong enforcement of new curriculum reform and the high social expectation to the urban and key school teachers. These make the teachers constantly reposition and adapt to their professional role, so that urban and key middle school teachers' approval of consciousness of researcher and developer, collaborator and facilitator, and role norms are significantly lower than rural and non-key middle school teachers'. 2) The consciousness of professional role for the rural backbone teachers is significantly higher than the non-backbone teachers', which is due to backbone teachers' own diathesis, more training and study opportunities. On the one hand, the backbone teachers have good ideological and 
Table 1.

Comparison to Sichuan rural teachers' professional consciousness.

\begin{tabular}{|c|c|c|c|c|c|c|}
\hline Scale & 1 & 2 & 3 & 4 & 5 & 6 \\
\hline City & $3.30 \pm .60$ & $3.61 \pm .97$ & $3.53 \pm .74$ & $4.04 \pm .94$ & $4.00 \pm .88$ & $3.30 \pm .75$ \\
\hline Country & $3.00 \pm .71$ & $3.86 \pm .95$ & $3.75 \pm .75$ & $4.46 \pm .77$ & $4.46 \pm .58$ & $3.26 \pm .84$ \\
\hline$t$ & $2.95^{* *}$ & -1.78 & -1.93 & $-3.54^{* * *}$ & $-5.13^{* * *}$ & .30 \\
\hline Backbone Teachers & $3.08 \pm .67$ & $3.94 \pm .82$ & $3.88 \pm .64$ & $4.64 \pm .50$ & $4.59 \pm .40$ & $3.22 \pm .82$ \\
\hline Non-Backbone Teachers & $3.07 \pm .70$ & $3.52 \pm 1.10$ & $3.33 \pm .81$ & $3.73 \pm 1.04$ & $3.79 \pm .87$ & $3.35 \pm .79$ \\
\hline$t$ & .12 & $3.46^{* *}$ & $5.74^{* * *}$ & $9.47^{* * *}$ & $9.97^{* * *}$ & -1.21 \\
\hline Key Middle School & $3.17 \pm .61$ & $3.65 \pm .93$ & $3.48 \pm .74$ & $3.97 \pm .92$ & $3.88 \pm .87$ & $3.30 \pm .75$ \\
\hline Non-Key Middle School & $3.05 \pm .70$ & $3.83 \pm .95$ & $3.78 \pm .72$ & $4.46 \pm .78$ & $4.48 \pm .58$ & $3.24 \pm .84$ \\
\hline$t$ & 1.23 & -1.35 & $-2.82^{* *}$ & $-4.14^{* * *}$ & $-6.16^{* * *}$ & .55 \\
\hline Chinese-Math-Foreign Teachers & $3.09 \pm .69$ & $3.87 \pm .92$ & $3.75 \pm .73$ & $4.40 \pm .85$ & $4.42 \pm .66$ & $3.24 \pm .84$ \\
\hline Other Subjects Teachers & $3.11 \pm .68$ & $3.50 \pm 1.30$ & $3.51 \pm .70$ & $4.13 \pm .80$ & $4.10 \pm .78$ & $3.35 \pm .75$ \\
\hline$t$ & -1.8 & $2.3^{*}$ & 1.92 & 1.87 & $2.48^{*}$ & -.77 \\
\hline Primary School Teachers & $2.94 \pm .76$ & $3.79 \pm 1.25$ & $3.53 \pm .84$ & $3.82 \pm 1.18$ & $4.06 \pm .88$ & $3.38 \pm .98$ \\
\hline Junior Middle School Teachers & $3.05 \pm .68$ & $3.88 \pm .83$ & $3.84 \pm .68$ & $4.65 \pm .49$ & $4.58 \pm .40$ & $3.21 \pm .81$ \\
\hline Senior Middle School Teachers & $3.34 \pm .49$ & $3.31 \pm .95$ & $3.20 \pm .69$ & $3.45 \pm .84$ & $3.40 \pm .80$ & $3.32 \pm .62$ \\
\hline$F$ & $3.33^{*}$ & $5.51^{* *}$ & $12.62^{* * *}$ & $57.33^{* * *}$ & $66.69^{* * *}$ & .89 \\
\hline Teachers in the Second Rank of Teaching & $2.98 \pm .76$ & $3.69 \pm 1.01$ & $3.61 \pm .81$ & $4.20 \pm .99$ & $4.23 \pm .78$ & $3.19 \pm .76$ \\
\hline Teachers in the First Rank of Teaching & $3.10 \pm .64$ & $3.86 \pm .92$ & $3.74 \pm .71$ & $4.42 \pm .76$ & $4.37 \pm .67$ & $3.31 \pm .80$ \\
\hline Teachers of High-Ranking & $3.21 \pm .57$ & $3.88 \pm .81$ & $3.84 \pm .58$ & $4.53 \pm .52$ & $4.52 \pm .48$ & $3.29 \pm .95$ \\
\hline$F$ & 1.93 & 1.04 & 1.64 & $3.13^{*}$ & 2.72 & .55 \\
\hline
\end{tabular}

Note: 1 = consciousness of status; 2 = consciousness of knowledge imparter and executor; $3=$ consciousness of researcher and curriculum developer; $4=$ consciousness of collaborator and facilitator; $5=$ consciousness of professional role norms; $6=$ consciousness of professional role experience.

Table 2.

The correlation values between rural teachers' consciousness of professional role and work autonomy.

\begin{tabular}{ccccccc}
\hline Scale & 1 & 2 & 3 & 4 & 5 & 6 \\
\hline Autonomy of School Operation Management & $.287^{* * *}$ & -.081 & -.109 & $-.143^{*}$ & $-.143^{*}$ & $.155^{*}$ \\
Autonomy of Professionalization and Curriculum Reform & $.181^{* *}$ & -.102 & .030 & -.106 & -.153 & .078 \\
Autonomy of Student Performance Assessment & $.244^{* * *}$ & $.155^{*}$ & $.201^{* *}$ & $.247^{* * *}$ & $.256^{* * *}$ & .099 \\
Autonomy of Student Behavior Management & $.227^{* * *}$ & $.316^{* * *}$ & $.266^{* * *}$ & $.391^{* * *}$ & $.361^{* * *}$ & $.128^{*}$ \\
Autonomy of Carrying out Extra-Curricular Activities & $.227^{* * *}$ & $.265^{* * *}$ & $.228^{* * *}$ & $.265^{* * *}$ & $.254^{* * *}$ & $.285^{* *}$ \\
Autonomy of Class Teaching & $.177^{* *}$ & $.174^{* *}$ & $180^{* *}$ & $.282^{* * *}$ & $.259^{* * *}$ & $.194^{* *}$ \\
\hline
\end{tabular}

Note: 1 = consciousness of status, $2=$ consciousness of knowledge imparter and executor; $3=$ consciousness of researcher and curriculum developer, $4=$ consciousness of collaborator and facilitator; $5=$ consciousness of professional role norms, $6=$ consciousness of professional role experience.

political quality, noble teacher's ethics cultivation, healthy body and mind diathesis, solid professional knowledge, systematic education theory, practiced business skills, and consciousness of actively carrying out creative teaching (Xie, 2010); On the other hand, in the recent ten years, our country provides backbone teachers with training and study opportuni- ties through kinds of channels, which develop their personal theories that help them criticize and rethink the role, promote understanding and grasping of the role recognition, and even are good for achieving the accordance between role behavior and role playing, between educational thinking mode and practical teaching mode. 3) The rural Chinese-Math-English teach- 
Table 3.

Factors and parameters of regression analysis for teachers' professional role consciousness predicting work autonomy.

\begin{tabular}{|c|c|c|c|c|c|}
\hline Dependent Variables & Independent Variables & $\beta$ & $R^{2}$ (adjusted) & $t$ & $F$ \\
\hline Autonomy of School Operation Management & $\begin{array}{l}1 \\
3\end{array}$ & $\begin{array}{c}.479 \\
-.279\end{array}$ & $\begin{array}{l}.069 \\
.104\end{array}$ & $\begin{array}{c}4.82^{* * *} \\
-3.09^{* * *}\end{array}$ & $13.17^{* * *}$ \\
\hline Autonomy of Professionalization and Curriculum Reform & $\begin{array}{l}1 \\
5\end{array}$ & $\begin{array}{c}.308 \\
-.304\end{array}$ & $\begin{array}{l}.025 \\
.051\end{array}$ & $\begin{array}{c}2.75^{* *} \\
-2.67^{* *}\end{array}$ & $6.89^{* * *}$ \\
\hline Autonomy of Student Performance Assessment & $\begin{array}{l}5 \\
1\end{array}$ & $\begin{array}{l}.287 \\
.274\end{array}$ & $\begin{array}{l}.059 \\
.104\end{array}$ & $\begin{array}{l}3.68^{* * *} \\
3.49^{* *}\end{array}$ & $13.89^{* * *}$ \\
\hline Autonomy of Student Behavior Management & $\begin{array}{l}4 \\
5\end{array}$ & $\begin{array}{l}.420 \\
.266\end{array}$ & $\begin{array}{l}.142 \\
.181\end{array}$ & $\begin{array}{l}6.57^{* * *} \\
3.42^{* *}\end{array}$ & $25.91^{* * *}$ \\
\hline Autonomy of Carrying out Extra-Curricular Activities & $\begin{array}{l}6 \\
5 \\
1\end{array}$ & $\begin{array}{l}.270 \\
.305 \\
.207\end{array}$ & $\begin{array}{l}.068 \\
.107 \\
.120\end{array}$ & $\begin{array}{l}3.16^{* *} \\
3.18^{* *} \\
2.08^{*}\end{array}$ & $11.23^{* * *}$ \\
\hline Autonomy of Class Teaching & $\begin{array}{l}4 \\
6\end{array}$ & $\begin{array}{l}.286 \\
.167\end{array}$ & $\begin{array}{l}.078 \\
.097\end{array}$ & $\begin{array}{l}4.12^{* * *} \\
2.40^{*}\end{array}$ & $13.07^{* * *}$ \\
\hline
\end{tabular}

Note: $1=$ consciousness of status; $3=$ consciousness of researcher and curriculum developer; $4=$ consciousness of collaborator and facilitator; $5=$ consciousness of professional role norms; 6 = consciousness of professional role experience.

ers' consciousness of professional role is higher than other subjects' teachers which may be related to the current educational system. Under the current educational system, students, parents and schools pay more attention to Chinese, Math and English than other subjects, which makes the Chinese-Math-English teachers' status higher than other subjects' teachers and approve more their consciousness of professional role. 4) The survey shows reasons for a significant difference in the consciousness of professional role between primary and middle school teachers. Firstly, from the point of the demands of students development, senior high school education is the important stage of the whole basic education that is not only the basis for further study to the students and lay a solid foundation for students' lifelong development, but also the key period to cultivate high quality human resources. So, senior high school teachers have higher consciousness of role status than primary and junior middle school teachers. In the meantime, senior high school students' sense of independence and critical thinking is in the developing period, so the consciousness of senior high school teachers as the imparter and practitioner of knowledge and teaching material is lower than primary and junior middle school teachers'. Secondly, maybe quality education is carried out more fully and education reform reflects more lively in primary school. While the entrance examinations are prior in junior and senior high school, and evaluation system has not changed too much today, primary school teachers truly feel the changes of the whole atmosphere in classroom, curriculum, and school brought by the teachers' role transformation, so their understanding of the consciousness of cooperator and facilitator, and professional role norms is significantly higher than senior high school teachers'. 5) There is no difference in gender, teaching aging and education background in rural teachers' consciousness of professional role, which shows teachers from every age bracket are faced with the approval of teacher's professional role. The reasons are that (Shen, 2005): on the one hand, from the perspective of teachers' professional development, teachers will encounter difficulties and setbacks in the professional development process, and will experience hard times which create doubt, negation and other imbalance mentality to the original approval of professional role, and even professional burnout for some teachers. On the other hand, the educational reform and the transformation of the teachers' role are strongly advocated in recent years, which may be a new problem for every teacher. Especially today when the society develops rapidly and network technology is widely used, old teachers or bachelor-degree teachers are faced with the psychological stress brought by professional role transformation and anxiety produced by professional approval that can not be established, so their problems are never smaller than a young or college-degree teacher'. All these require teachers to establish or improve the approval of the professional role.

\section{The Relationship Analysis between Consciousness of Professional Role and Work Autonomy of the Rural Teachers}

This study shows that the higher the consciousness of job status, the better the role experience, the stronger the teachers' work autonomy, which can positively predict the teachers' work autonomy. That is because self consciousness is the medium to take part in various social practice activities. If the teachers improve their consciousness of professional role, the initiative of self shaping will be enhanced and the education-teaching autonomy which is the intrinsic psychological motivation for the teachers to work will get more attention.

This study results show that there are negative correlations between five dimensions of consciousness (consciousness of imparter and executor, of researcher and developer, of collaborator and facilitator, of role norms) and two dimensions of work autonomy (work autonomy of school operation management, work autonomy of professionalization and curriculum reform). In the meantime, rural teachers' consciousness of researcher and developer as well as role norms can negatively predict the work autonomy of school operation management and work autonomy of professionalization and curriculum reform. Maybe that is because under the current system of education management in our country, schools apply administration management and the leaders determine and execute the school operation management, so teachers as the researcher and developer can enhance the teaching related work autonomy in student performance assessment, student behavior management, carrying out extra-curricular activities, and class teaching, and can weaken 
the autonomy of school operation management. In the mean time, because of kinds of tests and entrance examinations pressure in different stages in primary and middle schools, teachers can not appropriately understand and grasp the consciousness of role norms, and so lack autonomy of teacher professionalization and curriculum reform.

\section{Acknowledgements}

This article is Sichuan province philosophy and social sciences key research base, one of the achievements for the project of Sichuan teachers education research center, Sichuan rural teachers' professional role consciousness research (TER2009017).

\section{REFERENCES}

Ding, S. S., \& Zhang, X. S. (1992). Social role theory. Shanghai Academy of Social Sciences Press, 60-65.

Feng, L. P. (2006). A study on the stability of professional role consciousness of the young and middle adulthood teacher in university. Central South University Master Degree Thesis, 15-16.

Liang, Y. H., \& Pang, L. J. (2005). The concerning teachers' role consciousness: The connotation, structure and value. Journal of Education Science (China), 21, 39-42.
Jiang, P. (2008). Research on the role awareness of beginning teachers in primary school. Liaoning Normal University Master Degree Thesis, 11-12.

Fang, K. K., \& Ding, X. H. (2007). Education job autonomy and job satisfaction. Tsinghua Journal of Education, 28, 40-47.

Menlo Hackman, J. R., \& Oldham, G. R. (1980). Work redesign, Menlo Park A: Addison-Wesley, 128-136.

Yao, J. H., \& Shen, J. L. (2010). Construction and revision of teaching intrinsic autonomy questionnaire for primary and middle school teachers. Journal of Psychological Development and Education (China), 3, 302-307.

Yang, B., Xia, L. X., \& Huang, X. T. (2009). The development of teacher work autonomy scale in China. Journal of Southwest University (Social Sciences Edition), 35, 17-20.

$\mathrm{Wu}, \mathrm{L}$. K. (2009). Why do teachers alienate new curriculum reform, Journal of Research in Educational Development, 4, 47-50.

Zhang, P., \& Ye, Z. M. (2010). The bottom view: the new curriculum reform of rural teachers. Journal of Education Research Monthly (China), 7, 53-56.

Xie, L. P. (2010). The recognition of define of the back-bone teachers. Journal of the New Curriculum Teaching Research Version, 18, 8485.

Shen, Z. F. (2005). A research on the professional role-identity of Shanghai primary and middle school teachers. Journal of Psychological Science, 28, 723-726. 